\title{
Anti-Mullerian Hormone as A new Marker for Diagnosis of Poly Cystic Ovary Syndrome
}

\author{
Abdel Monieum Mohamed Zakaria, Ahmed Osama, Ahmed Kamal Mohamed Abo Sheashea \\ Department of Obstetrics and Gynecology, Faculty of Medicine Al-Azhar University
}

\begin{abstract}
Background: Polycystic ovary syndrome (PCOS) is a complex disease characterized by various endocrine disorders that are the potential cause of anovulation and hyperandrogenism. This heterogeneous syndrome affects about 5$10 \%$ of reproductive-age female population and it can be considered the most common endocrine disorder affecting women during reproductive life. PCOS is a multifactorial polygenic disease. Genes that regulate steroidogenesis and folliculogenesis are interested. Hence, AMH measurement has been found to offer a relatively high specificity and sensitivity as a diagnostic marker.

Objectives: The study aimed to assess the accuracy of AMH in the prediction of PCOS in patients admitted to Elsayed Galal and El Hussein University Hospital.

Subjects and methods: This was a retrospective study that was done on 130 women, divided into two groups, group I include 100 PCOS patients and group II, 30 control subject.

Results: The results of this study showed that there was no significant difference between the two groups regarding age, while there was a significant increase in BMI in patients more than in control. The level of LH showed a significant increase in patients more than in the control. The level of FSH showed a significant decrease in patients less than in the control. The Testosterone showed a significant increase in patients more than in the control. The androstenedione showed a significant increase in patients more than in the control group. The AMH showed a highly significant increase in patients more than in the control and in turn the number of follicles in group II (patients) was significantly higher than in the control. The sensitivity of AMH in diagnosis PCOS was 98.0, specificity was $80.0 \%$ and the total accuracy was 93.0 at the cutoff of point 0.911 .

Conclusion: Additional advantages of AMH as diagnostic tool are that it is biological, objective, quantitative marker not affected by day of menses or OCP intake. So in future, more studies should be undertaken to validate its role as diagnostic tool for PCOS.

Keywords: Anti Mullerian Hormone - Diagnosis - Poly Cystic Syndrome.
\end{abstract}

\section{INTRODUCTION}

Polycystic ovary syndrome (PCOS) is a complex disease characterized by various endocrine disorders that are the potential cause of anovulation and hyperandrogenism. This heterogeneous syndrome affects about $5-10 \%$ of reproductive- age females population and it can be considered the most common endocrine disorder affecting women during reproductive life. PCOS is a multifactorial polygenic disease: genes involved in insulin-resistance, genes that encode inflammatory factors and genes that regulate steroidogenesis and folliculogenesis are interested ${ }^{(\mathbf{1})}$. Although PCOS is the most frequent endocrine disorder in women of reproductive age, the diagnosis of the syndrome remains one of the most challenging issues in endocrinology, gynecology and reproductive medicine. PCOS is a diagnosis of exclusion and is defined by the Rotterdam classification from 2003 requiring at least 2 out of 3 criteria: oligo and/or anovulation, clinical and/or biochemical hyperandrogenism (HA) and polycystic ovaries on ultrasound ${ }^{(2)}$.

Anti-Meullerian hormone (AMH) is a glycoprotein hormone with a molecular weight of 140 $\mathrm{kDa}$ that belongs to the superfamily of the transforming growth factor beta (TGF-b) ${ }^{(3)}$. AMH acts as a regulator of folliculogenesis, it is produced by the granulosa cells of follicles from the stage of the primary follicle to the initial formation of the antrum. Its production begins in the perinatal period, it increases gradually until puberty, remaining stable in the reproductive period and it becomes very low after the menopause ${ }^{(4)}$.

Women with PCOS have an increased number of small follicles in the pre-antral and antral stage, and therefore it is observed that their AMH serum concentrations are higher than their counterpart (5). Females with PCO have higher levels of AMH whether obese or lean as compared to a female with no PCOS. This has been reported in a study that recruited sample from a community that included both lean and overweight women. Elevated circulating AMH levels were found among PCOS females versus non-PCOS women, regardless of Insulin resistance and adiposity status ${ }^{(6)}$. Furthermore, AMH levels are positively correlated with individual features of PCOS, including LH concentrations, testosterone, mean ovarian volume and the number of ovarian follicles as reported by. Laven et al. ${ }^{(7)}$. Hence as a diagnostic marker, AMH measurement has been found to offer a relatively high specificity and sensitivity (92 and 67\% respectively) for PCOS. Thus in situations where accurate ultrasound data are not available or where there is lack of adequate quality of equipment used for sinology ${ }^{(8)}$, AMH could be used instead of the follicle count as a diagnostic criterion for PCOS ${ }^{(9)}$. 


\section{AIM OF THE WORK}

The aim of the present work was to assess the accuracy of AMH in the prediction of PCOS in the patients follow up in Kafr El-Sheikh General Hospital and El Hussein university hospital.

\section{PATIENTS AND METHODS}

This retrospective study was done at Kafr-El Sheikh General Hospital and El Hussein University Hospital and done on 130 women.

\section{Ethical approval:}

The study was approved by the Ethics Board of Al-Azhar University and an informed written consent was taken from each participant in the study.

\section{$\checkmark 100$ PCOS patients}

Diagnosis criteria as two of the following: 1) prolonged oligo-ovulation (6 or fewer menses per year) or anovulation 2) clinical hirsutism defined by FerimanGallowey score > 7, acne, androgenic alopecia and/or biochemical signs of HA and 3) PCO morphology on ultrasound examination. Biological HA was defined as total testosterone > $2.4 \mathrm{mmol} / \mathrm{L}$ or $0.69 \mathrm{ng} / \mathrm{ml}$. Cushing's syndrome, non-classical adrenal 21hydroxylase deficiency, hyperprolactinemia or androgen-secreting neoplasms were excluded. Subjects were maintained on free diet and standard OGTT $(75 \mathrm{~g}$ glucose) was performed in PCOS patients. Glucose intolerance (IGT) and impaired fasting glucose (IFG) were defined by 2006 American Diabetes Association (ADA) criteria. Insulin resistance was evaluated by Homeostasis Model Assessment (HOMA-IR) index.

\section{- Control group}

It included 30 women that were consulting in the Obstetrics and Gynecology Department of the same University Hospital for normal reproductive status with regular menses, proven fertility (at least one child) and with no clinical or biochemical signs of HA.

\section{Hormonal immunoassays.}

All assays were done at the research laboratory of the University of Medicine and Pharmacy, Bucharest. Blood samples were collected during the second to fifth day of a spontaneous menstrual cycle or during amenorrhea, after an overnight fast and stored at $-20^{\circ} \mathrm{C}$. Serum AMH was measured in duplicate using ultrasensitive ELISA (AMH-EIA, Beckman Coulter, Villepinte, France). Intra-assay coefficient of variation was $12 \%$. The detection limit was $0.7 \mathrm{pmol} / \mathrm{L}$. Insulin was measured by radioimmunoassay (Adaltis RIA/PEG, Rome, Italy) with a sensitivity of $1 \mathrm{mIU} / \mathrm{ml}$ and $29 \%$ cross-reactivity with pro-insulin. Testosterone, LH, FSH and PRL measurements were performed by Beckman Access (B) Immunoassay system (Beckman-Coulter, Chaska, MI, USA). Plasma glucose was measured by glucose-oxidized method on a Hitachi 912.

\section{The inclusion criteria were:}

1. Presence of both ovaries,

2. No use of hormone therapy in the 3 months preceding the study,

3. No history of premature ovarian failure,

4. No previous ovarian surgery and

5. No exposure to cytotoxic drugs or pelvic radiation therapy.

\section{Exclusion criteria}

Women who fulfilled the following criteria were excluded from the study:

1. Pregnancy and

2. Breastfeeding.

\section{Results}

This retrospective study that was done at Elsayed Galal and El Hussein University Hospital and was done on 130 women, divided into two groups, 100 PCOS patients and 30 control subjects. The demographic, clinical and laboratory findings were assessed as follows; in control group, the mean age was $29.0 \pm 3.93$ years, while in patients group the mean age was $30.0 \pm 4.73$ years. On comparing the two groups, it was found that there was no significant difference between the two groups $(p>0.05)$.

Regarding body mass index, in "control group" the BMI was $23.8 \pm 1.57$, while in patients group the mean BMI was $26.6 \pm 2.18$. It was found that there was a significant increase in BMI in POCS patients more than in the control group $(\mathrm{p}<0.01)$.

Table (1) showed that the mean level of LH in the control group was $4.2 \pm 0.33$ and in patients group was $6.9 \pm 0.42 \mathrm{IU} / \mathrm{l}$. There was a significant increase in LH in patients' group more than in the control group (p $<0.01$ ). The mean level of FSH was $6.3 \pm 0.38 \mathrm{IU} / \mathrm{l}$ while in patients group was $5.9 \pm 0.34 \mathrm{IU} / \mathrm{L}$. On comparing the two studied groups, it was found that there was a significant decrease in FSH in patients group less than in control group ( $\mathrm{p}<0.01)$. The testosterone level in control group was $0.29 \pm 0.02 \mathrm{ng} / \mathrm{ml}$, while in patients group was $0.46 \pm 0.03 \mathrm{ng} / \mathrm{ml}$. There was a highly significant increase in testosterone in patients more than in the control group $(\mathrm{p}<0.05)$.

The androsternedione level in control group was $1.49 \pm 0.12 \mathrm{ng} / \mathrm{ml}$ while in patients group was $2.64 \pm$ $0.21 \mathrm{ng} / \mathrm{ml}$. There was a significant increase in androstenedione in patients group more than in the control group $(\mathrm{p}<0.01)$.

The AMH level in control group was $33.8 \pm$ $2.39 \mathrm{pmol} / \mathrm{l}$ while in patients group was $81.9 \pm 6.80$ $\mathrm{pmol} / \mathrm{l}$. There was a highly significant increase in AMH in patients group more than in the control group (p < 0.01 ). The mean number of follicle with diameter 2-9 $\mathrm{mm}$, in group I was $6.9 \pm 2.62$, while in patients group was $18.3 \pm 5.34$. There was a significant increase in the number of follicle in patients group more than in the control group $(\mathrm{p}<0.05)$. 
Table (1): Comparison between the two studied groups concerning hormonal assay

\begin{tabular}{|l|c|c|c|}
\hline & $\begin{array}{c}\text { Control Group I } \\
(\mathbf{n = 3 0})\end{array}$ & $\begin{array}{c}\text { Patients Group II } \\
(\mathbf{n = 1 0 0})\end{array}$ & $\mathbf{p}$ \\
\hline $\begin{array}{c}\text { LH (IU/liter) } \\
\text { Mean } \pm \text { S.D. }\end{array}$ & $4.2 \pm 0.33$ & $6.9 \pm 0.42$ & $<0.001^{*}$ \\
\hline $\begin{array}{c}\text { FSH (IU/liter) } \\
\text { Mean } \pm \text { S.D. }\end{array}$ & $6.3 \pm 0.38$ & $5.9 \pm 0.34$ & $<0.01^{*}$ \\
\hline $\begin{array}{c}\text { Testosterone (ng/ml) } \\
\text { Mean } \pm \text { S.D. }\end{array}$ & $0.29 \pm 0.02$ & $0.46 \pm 0.03$ & $<0.001$ \\
\hline $\begin{array}{c}\text { Androstenedione } \\
\text { (ng/ml) } \\
\text { Mean } \pm \text { S.D. }\end{array}$ & $1.49 \pm 0.12$ & $2.64 \pm 0.21$ & $<0.001$ \\
\hline $\begin{array}{c}\text { AMH (pmol/liter) } \\
\text { Mean } \pm \text { S.D. }\end{array}$ & $33.8 \pm 2.39$ & $81.9 \pm 6.80$ & $<0.001$ \\
\hline $\begin{array}{c}\text { 2- to 9-mm follicle no. } \\
\text { Mean } \pm \text { S.D. }\end{array}$ & $6.9 \pm 2.62$ & $18.3 \pm 5.34$ & $<0.001$ \\
\hline
\end{tabular}

*: Statistically significant at $\mathrm{p} \leq 0.05$

Table (2) showed the sensitivity, specificity and accuracy of AMH in diagnosis of the PCOs. From ROC curve (Figure 1), it was found that there was a two cut off value of AMH in predicting the PCOs patients at 50 and 60 , the sensitivity was 95.0 and 98 respectively, while the specificity was 82.0 and $80.0 \%$ and the accuracy was 92.0 and 93.0 in the two cut off value.

Table (2): The sensitivity, specificity and accuracy of AMH in diagnosis the PCOs.

\begin{tabular}{|c|c|c|c|c|c|}
\hline $\begin{array}{c}\text { Area under } \\
\text { the curve }\end{array}$ & P value & $\begin{array}{c}\text { Cut off } \\
\text { value }\end{array}$ & Sensitivity & Specificity & Accuracy \\
\hline 0.907 & $0.0001 *$ & 50 & 95.0 & 82.0 & 92.0 \\
\hline 0.911 & $0.0001 *$ & 60 & 98.0 & 80.0 & 93.0 \\
\hline
\end{tabular}

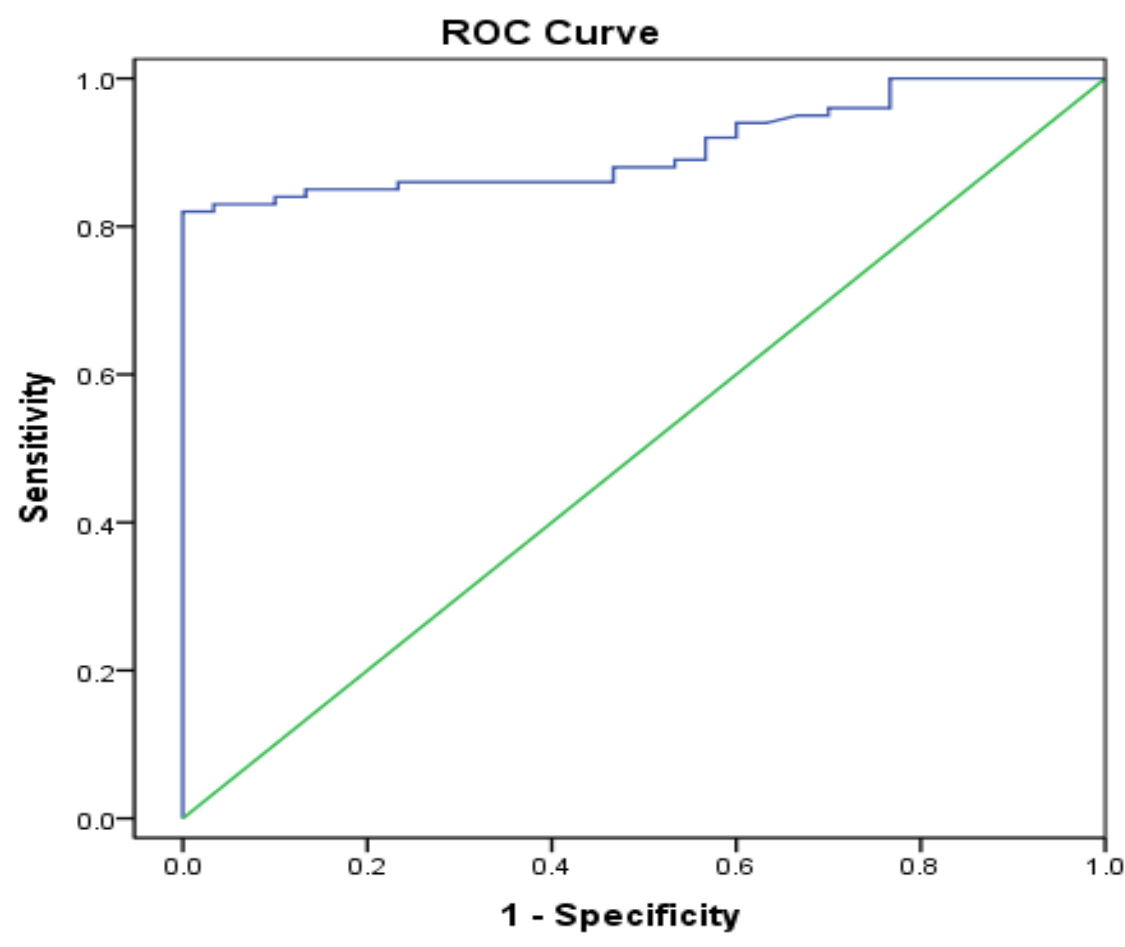

Diagonal segments are produced by ties.

Figure (1): ROC curve for AMH. 


\section{DISCUSSION}

The polycystic ovary syndrome (PCOS) is the most frequent endocrine disorder in women of reproductive age and its diagnosis remains one of the most challenging issues in endocrinology, gynecology, and reproductive medicine (10). For many years, different combinations of clinical (irregular menstrual cycles, hirsutism, and acne), biological (elevated serum testosterone or androstenedione levels or increased LH/FSH ratio) and ultrasound (U/S) criteria have been proposed with very little international consensus. Indeed, the conservative definition for PCOS that was issued from a conference held in the National Institutes of Health in $1990^{\text {(11) }}$ did not satisfy many authors because it omitted the U/S criteria. More recently, during another consensus conference held in Rotterdam in $2003^{(12)}$, it has been proposed to include in the definition of PCOS the U/S criteria that are considered at the present time as the most specific, namely an increased ovarian volume $(>10 \mathrm{ml})$ and/or the presence of 12 or more follicles in each ovary measuring $2-9 \mathrm{~mm}$ (13)

In this study, we investigated whether AMH measurement could be a valuable diagnostic marker of PCOS. Indeed, numerous studies in the literature suggest that $\mathrm{AMH}$ is a potential marker of the ovarian follicle pool. In 2003, Fanchin et al. ${ }^{(14)}$ demonstrated that the antral follicle count was closely related to the serum AMH level on cycle $\mathrm{d} 3$ in infertile women, in a stronger way more than those obtained with other hormonal markers such as inhibin B, estradiol, or FSH. Later, several teams reported a strong increase (2- to 4fold) of serum AMH levels in PCOS patients, in close relationship with the increase in the small antral follicle number $(\mathrm{FN}){ }^{(7)}$.

Moreover we showed that the correlation between AMH and the small antral follicle count also stands in normal women. Thus, all these data led to the conclusion that AMH could be the best available biological marker of the ovarian early antral FN, both in fertile and infertile normoovulatory women and in PCOS patients. Moreover, it was recently demonstrated that the measurement of serum AMH levels was highly reproducible from one cycle to another, a fact that underlines its robustness as a biological marker of the ovarian follicle status ${ }^{(15)}$.

In our study the age of the two groups was matched. In control group the mean age was $29.0 \pm 3.93$ years, while in patients group the mean age was $30.0 \pm$ 4.73 years. On comparing the two groups, it was found that there was no significant difference. This result agrees with study carried out by Pigny et al. ${ }^{(9)}$. This study was carried out on two groups PCOS and controls, the mean age in both groups was 29.4 years and 29.0 years respectively. Also, there was no significant difference between the two groups regarding the age ${ }^{(9)}$.

In this study, the body mass index in patients' group was significantly higher than in the control group.
This result is in agreement with the fact that PCOS makes it more difficult for the body to use the hormone insulin, which normally helps convert sugars and starches from foods into energy. This condition is called insulin resistance and it can cause insulin and sugar - glucose - to build up in the bloodstream ${ }^{(16)}$.

The LH level (Iu/litter) in our groups showed a significant increase in patients more than in the control $(6.9 \pm 0.42$ and $4.2 \pm 0.33$ respectively). This is in agreement with Yildiz et al. ${ }^{(16)}$ who found that the LH levels in PCOS patients are also significantly higher when compared to non-PCOS patients $(\mathrm{p}<0.001)$. Also, Pigny et al. ${ }^{(9)}$ and Lin et al. ${ }^{\left({ }^{(18)}\right.}$ stated that there was an apparent correlation between AMH and $\mathrm{LH}$ because they found that $\mathrm{LH}$ was elevated in patients with PCOS who also had very high AMH levels.

In this study, the mean level of FSH in control group was $6.3 \pm 0.38 \mathrm{IU} / \mathrm{l}$ while in patients' group was $5.9 \pm 0.34 \mathrm{IU} / \mathrm{L}$. On comparing the two studied groups regarding FSH it was found that there was a significant decrease in FSH in patients group less than in control group. According to Pellat et al. ${ }^{(17)}$, FSH does not have an effect on AMH production and mRNA expression of $\mathrm{AMH}$ in granulosa cells, but there is a significant reduction (up to $30 \%$ ) in $\mathrm{AMH}$ after $\mathrm{FSH}$ administration in PCOS patients. The reason for this reduction is yet to be investigated. LH levels in PCOS patients are also significantly higher when compared to non-PCOS patients $(\mathrm{p}<0.001)$.

The AMH level in our results, was found in control group to be $33.8 \pm 2.39 \mathrm{pmol} / \mathrm{l}$ while in patients' group was $81.9 \pm 6.80 \mathrm{pmol} / \mathrm{l}$. There was a highly significant increase in AMH in patients' group more than in the control group. Until now, the cause of increased AMH levels in PCOS patients is still inconclusive. One theory stated that high levels of androgens may be the cause of PCOS. Singer et al. ${ }^{(19)}$ said that there is a relationship between AMH and androgens as AMH levels are elevated in PCOS patients with hyperandrogenism. Eldar-Geva ${ }^{(20)}$ stated that significant relationships between serum AMH levels and increasing testosterone, $\mathrm{LH}$ levels and increased number of follicles and ovarian volume on ultrasound examination ${ }^{(7)}$.

This study showed that AMH could be used as an alternative diagnostic tool in PCOS patients. Pigny et al. ${ }^{(9)}$ found that the specificity and sensitivity of serum AMH measurement reached 92 and $67 \%$, respectively. Lin et al. ${ }^{(18)}$ obtained the cutoff AMH level of $7.3 \mathrm{ng} / \mathrm{mL}$, giving $76 \%$ specificity $76 \%$ and 70 $\%$ sensitivity to predict PCOS. We obtained a cutoff value of $4.45 \mathrm{ng} / \mathrm{mL}$, lower than the findings of Lin $\boldsymbol{e t}$ al. ${ }^{(18)}$.

In our study the number of follicle with diameter 2-9 in group I was $6.9 \pm 2.62$, while in patients' group was $18.3 \pm 5.34$. There was a significant increase in the number of follicles in patients group more than in the control group (p < 0.05). In 2003, Fanchin et al. ${ }^{(14)}$ demonstrated that the antral follicle count was closely 
related to the serum AMH level on cycle $\mathrm{d} 3$ in infertile women, in a stronger way than those obtained with other hormonal markers such as inhibin B, estradiol, or FSH. Later, several teams reported a strong increase (2- to 4fold) of serum AMH levels in PCOS patients, in close relationship with the increase in the small antral FN. Moreover, it was shown that the correlation between $\mathrm{AMH}$ and the small antral follicle count also stands in normal women (21). Thus, all these data led to the conclusion that AMH could be the best available biological marker of the ovarian early antral FN both in fertile and infertile normo-ovulatory women and in PCOS patients. Moreover, it was recently demonstrated that the measurement of serum AMH levels was highly reproducible from one cycle to another, a fact that underlines its robustness as a biological marker of the ovarian follicle status ${ }^{(\mathbf{1 4})}$.

\section{CONCLUSION}

PCOS is a complex and common gynaecological condition and PCOM used currently in Rotterdam criteria is highly subjective and poorly reproducible. Though sensitivity and specificity of $\mathrm{AMH}$ alone is low and no single cut-off of AMH is diagnostic, still it is a promising diagnostic tool for PCOS as an adjunct to existing Rotterdam criteria especially when it is used to replace PCOM. Additional advantages of $\mathrm{AMH}$ as diagnostic tool are that it is biological, objective, quantitative marker not affected by day of menses or OCP intake. So in future, more studies should be undertaken to validate its role as diagnostic tool for PCOS.

\section{REFERENCES}

1. Bakeer E, Radwan R, Mandoury A et al. (2018): AntiMüllerian Hormone as A Diagnostic Marker in Egyptian Infertile Polycystic Ovary Syndrome Females: Correlations With Vitamin D, Total Testosterone, Dyslipidemia And Anthropometric Parameters. J Med Biochem., 37: 1-7.

2. Mishevska SJ, Krstevska B, Pemovska G et al. (2016): Sensitivity and specificity of anti-mülerian hormone in the diagnosis of polycystic ovary syndrome in a macedonian population of women of reproductive age: a cross-sectional study. Endocrine Oncology and Metabolism, 12: 94-101.

3. Dumont A, Robin G, Catteau-Jonard S et al. (2015): Role of anti-mullerian hormone in pathophysiology, diagnosis and treatment of poly-cystic ovary syndrome: a review. Reprod Biol Endocrinol., 13: 137-145.

4. Diefer DB (2011): Age-specific serum anti-mullerian hormone values for 17,120 women presenting to fertility centers within the United States. Fertil Steril., 95: 74750

5. Homburg R, Crawford G (2014): The role of AMH in anovulation associated with PCOS: a hypothesis. Human Reproduction, 29 (6): 1117 -1121.

6. Cassar S, Teede HJ, Moran LJ et al. (2014): Polycystic Ovary Syndrome and Anti-Müllerian Hormone: Role of insulin resistance, androgens, obesity and gonadotropins. Journal Clin Endocrinol (Oxf) ,
81(6):899-906.

7. Laven JS, Mulders AG, Visser JA et al. (2004): AntiMüllerian hormone serum concentrations in normoovulatory and anovulatory women of reproductive age. J Clin Endocrinol Metab., 89: 318323.

8. Johnstone EB, Rosen MP, Neril R et al. (2010): The polycystic ovary post-Rotterdam: a common, agedependent finding in ovulatory women without metabolic significance. The Journal of Clinical Endocrinology \& Metabolism, 95: 4965-4972.

9. Pigny P, Jonard S, Robert Y et al. (2006): Serum antiMullerian hormone as a surrogate for antral follicle count for definition of the polycystic ovary syndrome. J Clin Endocrinol Metab., 91: 941-945.

10. Abdel Hay MA, El-Berri SA, Sleem T et al. (2017): The role of anti-mullerian hormone as an indicator of reproductive health in women with obesity and concomitant polycystic ovary syndrome. Benha Med J., 34: $66-72$

11. Zawadski JK, Dunaif A (1992): Diagnostic criteria for polycystic ovary syndrome: towards a rational approach. In: Dunaif A, Givens JR, Haseltine F, Merriam G, eds. Polycystic ovary syndrome. Boston: Blackwell Scientific, Pp: 377-384

12. Dumesic DA, Richards JS (2013): Ontogeny of the ovary in polycystic ovary syndrome. Fertil Steril., 13: 100:23-38.

13. Balen A, Rajkowha M (2003): Polycystic ovary syndrome--a systemic disorder? Best Pract Res Clin Obstet Gynaecol., 17 (2): 263-74.

14. Fanchin R, Maria Schonauer L, Righini C et al. (2003): Serum AMH is more strongly related to ovarian follicular status than serum inhibin B, estradiol, FSH and LH on day 3. Hum Reprod., 18: 323-327.

15. Hwang IM, Sung NY, Cha SH (2013): Can high serum anti-Müllerian hormone levels predict the phenotypes of polycystic ovary syndrome (PCOS) and metabolic disturbances in PCOS patients? Clin Exp Reprod Med., 40: $135-140$.

16. Yildiz BO, Knochenhauer ES, Azziz R (2008): Impact of obesity on the risk for polycystic ovary syndrome. $\mathbf{J}$ Clin Endocrinol Metab., 93 (1): 162-168.

17. Pellatt L, Hanna L, Brincat $M$ et al. (2007): Granulosa cell production of anti-Mullerian hormone is increased in polycystic ovaries. J Clin Endocrinol Metab., 92 (1): 240-5.

18. Lin YH, Chiu WC, Wu CH et al. (2011): Antimullerian hormone and polycystic ovary syndrome. Fertil Steril., 96 (1): 230-5.

19. Singer T, Barad DH, Weghofer A (2009): Correlation of antimullerian hormone and baseline folliclestimulating hormone levels. Fertil Steril., 91 (6): 26169.

20. Eldar-Geva T, Margalioth EJ, Gal M et al. (2005): Serum anti-mullerian hormone levels during controlled ovarian hyperstimulation in women with polycystic ovaries with and without hyperandrogenism. Hum Reprod., 20: 1814-9.

21. Pigny P, Merlen E, Robert Y et al. (2003): Elevated serum level of anti-mullerian hormone in patients with polycystic ovary syndrome: relationship to the ovarian follicle excess and to the follicular arrest. J Clin Endocrinol Metab., 88 (12): 5957-62. 